\title{
Serological Identification of Animal Species of Meat Using Species-Specific Anti-Serum Albumin Antibodies Obtained by Immunoadsorbent Chromatography
}

\author{
Tsuneo KAMIYAMA, Yasuji KATSUBE and Kiyoshi IMAIZUMI \\ Department of Veterinary Science, National Institute of Health, \\ Shinagawa-ku, Tokyo 141
}

(Received for publication March 18, 1978)

\begin{abstract}
Species-specific antibody fraction against the bovine, pig, equine, dog, cat or goat-sheep group was isolated from anti-serum albumin antiserum by immunoadsorbent chromatography. It was used for serological identification of the animal species of meat. By ring test and rocket immunoelectrophoresis, it was demonstrated that the purified antibody fractions were capable of identifying the animal species of meat whereas unfractionated antisera showed strong cross-reactions. The identification limit was about $0.5-$ $1.0 \%$ in concentration. The mixing ratio of meat of different animal species could be determined by the rocket iramunoelectrophoresis.
\end{abstract}

In the previous paper, it was demonstrated that cross-reacting antisera against serum albumins of different animal species were capable of identifying the animal species of meat by a passive hemagglutination inhibition test [6].

Recently, we found that immunoadsorbent chromatography served as a useful tool for the purification of species-specific antibody from cross-reacting antiserum [3]. In the present paper, studies were made on the purification of species-specific antibody fractions from antisera against serum albumins of various animal species and the usefulness of the purified antibody for the serological identification of the animal species of meat.

\section{Materials and Methods}

Serum albumins and antisera: Commercially available serum albumins were used: bovine albumin (BSA) (Armour Pharmaceutical Co., USA), goat albumin (GSA) (Miles Laboratories, Inc., USA), and sheep (SSA), pig (PSA), equine (ESA) and dog (DSA) albumins (Nutritional Biochemical Co., USA). Cat albumin (CSA) was also used after purified from a cat serum [5]. Groups of rabbits were immunized with each albumin in the same manner as described previously [6]. Antisera were stored at $-20^{\circ} \mathrm{C}$ after inactivation at $56^{\circ} \mathrm{C}$ for $30 \mathrm{~min}$.

Isolation of species-specific antibody fractions: For an experiment on the relationship between ruminant groups (Table 1), anti-BSA antiserum was fractionated with GSA and SSA column. As a result, a nonadsorbed fraction (BSA-sp fraction) and an adsorbed fraction on both (BSA-GSA-SSA-common fraction) or either one (BSA-GSA-common or BSASSA-common fraction) of the heterologous columns were isolated, as shown in Fig. 1. The BSA-sp fraction was purified further with a column linked with BSA. In the similar manner, GSA-sp, SSA-sp and GSA-SSA-common fractions were isolated from antiGSA or -SSA antiserum.

In experiments with 7 animal species (Table 3), each antiserum was fractionated with 6 heterologous columns and a homolgous column to obtain a species-specific fraction. From anti-GSA or -SSA antiserum the GSA-SSA-common fractions were obtained and pooled.

Meat antigens: The experiments were carried

分離精製した抗アルブミン抗体を用いて行う食肉の血清学的肉種鑑別法：神山恒夫・勝部泰次・今宗 清（国立 予防衛生研究所獣湥部) 
Fig. 1. Schematic pattern of immunoadsorbent chromatography

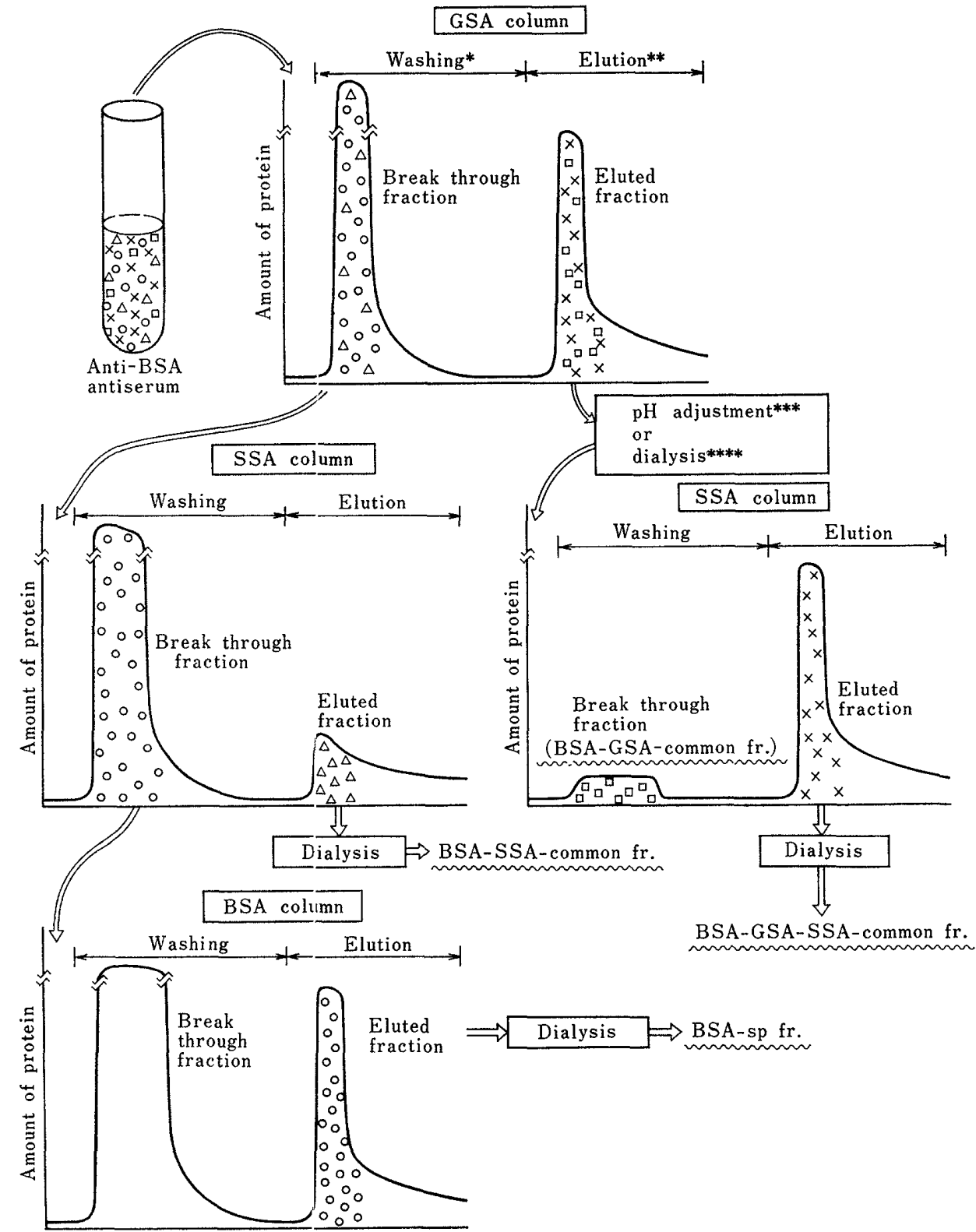

Remarks.

Fractionation of antibody populatiors from anti-BSA antiserum is illustrated.

*: Washing was done with $0.1 \mathrm{M}$ borate buffer containing $0.5 \mathrm{M} \mathrm{NaCl}, \mathrm{pH} 8.0$, or $0.1 \mathrm{M}$ Tris- $\mathrm{HCl}$ buffer containing $0.5 \mathrm{M} \mathrm{NaCl}, \mathrm{pH} 7.5$.

**: Elution was done with $0.17 \mathrm{M}$ glycine- $\mathrm{HCl}$ buffer containing $0.5 \mathrm{M} \mathrm{NaCl}$, pH 2.3, or $0.1 \mathrm{M}$ Tris$\mathrm{HCl}$ buffer containing $0.5 \mathrm{M} \mathrm{NaCl}$ and $3 \mathrm{M} \mathrm{KSCN}, \mathrm{pH} 7.5$.

***: When the glycine buffer was used for elution, $\mathrm{pH}$ was adjusted to neutral with $1 \mathrm{M}$ glycine- $\mathrm{NaOH}$ buffer, pH 10.

****: When the Tris buffer was used for elution, KSCN was removed by dialysis against KSCN-free Tris buffer. 
out with cattle, goat, sheep, pig, horse, dog and cat meats. Sampling of animal meats, saline extraction of antigen from meats, and preparation of adulterated samples were performed in such manner as described previously $[5,6]$.

Serological techniques: Passive hemagglutination (PHA) test was performed using sheep red blood cells (SRBC) coated with serum albumin by the aid of bis-diazotized benzidine [1] or glutaraldehyde [3] as coupling agent.

Ring test was carried out in a small tube, $2-3 \mathrm{~mm}$ in diameter. Meat extract was diluted 2-fold serially with $0.85 \% \mathrm{NaCl}$ containing $20 \%$ saccharose and dispensed into the tube to obtain a height of about $5 \mathrm{~mm}$. Then, antiserum or the purified antibody fractions was overlaid on the extract. The result was read after the tube was allowed to stand at room temperature for an hour.

Rocket immunoelectrophoresis [9] was performed with $0.8 \%$ agarose gel (barbital buffer, $\mathrm{pH} 8.6$ ) containing the isolated antibody fraction to a concentration of $80 \mu \mathrm{g} / \mathrm{m} l$. Five $\mu l$ of diluted or undiluted meat extract was poured into the well. Electro-

Table 1. Specificity of anti-serum albumin antisera and purified species-specific or cross-reactive antibody fractions

\begin{tabular}{lrrr}
\hline \multirow{2}{*}{$\begin{array}{l}\text { Antiserum* or } \\
\text { antibody fraction** }\end{array}$} & \multicolumn{3}{c}{ PHA titer*** with } \\
\cline { 3 - 5 } & BSA-SRBC & GSA-SRBC & SSA-SRBC \\
\hline Antiserum & & & \\
Anti-BSA & 2,560 & 1,280 & 1,280 \\
Anti-GSA & 1,280 & 2,560 & 1,280 \\
Anti-SSA & 2,560 & 2,560 & 5,120 \\
Antibody fraction & & & \\
BSA-sp fr. & 256 & $<4$ & $<4$ \\
GSA-sp fr. & $<4$ & 16 & 8 \\
SSA-sp fr. & $<4$ & 4 & 64 \\
BSA-GSA-common fr. & 8 & 16 & 16 \\
BSA-SSA-common fr. & 4 & 4 & 4 \\
GSA-SSA-common fr. & $<4$ & 128 & 128 \\
BSA-GSA-SSA-common fr. & 512 & 512 & 512 \\
\hline
\end{tabular}

Remarks.

*: Antiserum containing about $10 \mathrm{mg}$ of antibody per $\mathrm{ml}$.

**: Antibody fraction containing $1 \mathrm{mg}$ of antibody per $\mathrm{ml}$.

***: Passive hemagglutination titers are indicated as reciprocals of the highest dilution of antiserum or the antibody fraction giving positive agglutination. Coated SRBC were prepared with the aid of bis-diazotized benzidine as a coupling agent. phoresis was conducted at $2-4 \mathrm{~mA} / \mathrm{cm}$ for 5-6 hr at room temperature. After that, the gel was washed with $0.85 \% \mathrm{NaCl}$ and stained with $0.05 \%$ Coomassie brilliant blue R-250/25\% isopropanol/10\% acetic acid.

\section{Results}

From anti-ruminant serum albumin antisera, various antibody fractions were purified by immunoadsorbent chromatography. Antibody fractions capable of binding to both BSA and GSA columns, but not to SSA column, were collected from anti-BSA and anti-GSA antisera and pooled (BSAGSA-common fraction). In the similar manner, BSA-SSA-common and GSA-SSAcommon fractions were also obtained. Antibody fractions capable of binding to all the 3 kinds of columns were isolated from anti-BSA, anti-GSA and anti-SSA antisera and pooled (BSA-GSA-SSA-common fraction). Specificities of these antibody fractions were studied by the PHA test (Table 1). The species-specificity of the BSA-sp fraction was clearly demonstrated, while that of the GSA-sp and SSA-sp fractions was vague. The hemagglutinating activity

Table 2. Identiflcation of ruminant meat by ring test with anti-serum albumin antiserum and purifled antibody fraction

\begin{tabular}{llll}
\hline \multirow{2}{*}{$\begin{array}{l}\text { Antiserum* or } \\
\text { antibody fraction* }\end{array}$} & \multicolumn{3}{c}{ Meat extract antigen } \\
\cline { 2 - 4 } & Cattle & Goat & Sheep \\
\hline Antiserum & & & \\
Anti-BSA & $512 * * *$ & 128 & 256 \\
Anti-GSA & 512 & 512 & 512 \\
Anti-SSA & 256 & 256 & 512 \\
Antibody fraction & & & \\
BSA-sp fr. & 256 & $<2$ & $<2$ \\
GSA-SSA-common fr. & $<2$ & 256 & 512 \\
BSA-GSA-SSA-common fr. & 512 & 512 & 512 \\
\hline
\end{tabular}

Remarks.

*: Antiserum diluted 10 times.

**: Same fraction as indicated in Table 1.

***: Ring test was carried out in duplicate. The titers are indicated in reciprocals of the highest antigen dilution giving positive reaction. 
Table 3. Specificity of purified species-specific anti-serum albumin antibody

\begin{tabular}{lrrrrrrr}
\hline \multirow{2}{*}{$\begin{array}{l}\text { Antibody } \\
\text { fraction* }\end{array}$} & \multicolumn{7}{c}{ PHA } \\
\cline { 2 - 7 } & BSA-SRBC & GSA-SRBC & SSA-SRBC & PSA-SRBC & ESA-SRBC & DSA-SRBC & CSA-SRBC \\
\hline BSA-sp fr. & 256 & $<4$ & $<4$ & $<4$ & $<4$ & $<4$ & $<4$ \\
GSA-sp fr. & $<4$ & 16 & 8 & $<4$ & $<4$ & $<4$ & $<4$ \\
SSA-sp fr. & $<4$ & 4 & 64 & $<4$ & $<4$ & $<4$ & $<4$ \\
PSA-sp fr. & $<4$ & $<4$ & $<4$ & 256 & $<4$ & $<4$ & $<4$ \\
ESA-sp fr. & $<4$ & $<4$ & $<4$ & $<4$ & 512 & $<4$ & $<4$ \\
DSA-sp fr. & $<4$ & $<4$ & $<4$ & $<4$ & $<4$ & 512 & 16 \\
CSA-sp fr. & $<4$ & $<4$ & $<4$ & $<4$ & $<4$ & 8 & 256 \\
GSA-SSA-common fr. & $<4$ & 256 & 512 & $<4$ & $<4$ & $<4$ & $<4$ \\
\hline
\end{tabular}

Remarks.

*: Antibody fraction containing 100-200 $\mu \mathrm{g}$ of antibody per $\mathrm{ml}$.

** : Passive hemagglutination titers are indicated in reciprocals of the highest antibody dilution giving positive agglutination. Cocted SRBC were prepared with the aid of glutaraldehyde as a coupling agent.

of these 2 fractions was missing to some extent. The BSA-GSA-common and BSASSA-common fractions showed a low degree of hemagglutination against GSA- and SSASRBC. The BSA-GSA-SSA-cornmon fraction, as well as unfractionated antisera, agglutinated all the 3 kinds of coated SRBC.

These purified antibody fractions were used for the identification of ruminant meats by the ring test (Table 2). Since no species-specific antibody fraction for GSA or SSA could be isolated as mentioned above, the GSA-SSA-common fraction was used as a species-specific antibody fraction against the goat-sheep group. The BSA-sp fraction formed a precipitate only with cattle meat extract. The GSA-SSA-common fraction formed a precipitate with both goat and sheep meat extract, but not with cattle meat extract. These fractions were much superior in availability for specific identification to unfractionated antisera or the BSA-GSA-SSA-common fraction.

These results suggested that the purified species-specific antibody fractions might be capable of identifying the animal species of meat. Such antibody fractions were purified from antisera to serum albumin of the
7 animal species by the affinity chromatography. The specificity of these fractions obtained was evaluated by the PHA test (Table 3). BSA-sp, PSA-sp, ESA-sp, DSA-sp and CSA-sp fractions agglutinated their respective homologous coated SRBC strongly. On the other hand, GSA-sp and SSA-sp fractions showed a cross-reaction with each heterologous coated SRBC.

Figure 2 shows the precipitin pattern of rocket immunoelectrophoresis of sheep meat extract in agarose gel containing GSA-SSA-

Fig. 2. Rocket immunoelectrophoretic pattern of sheep meat extract

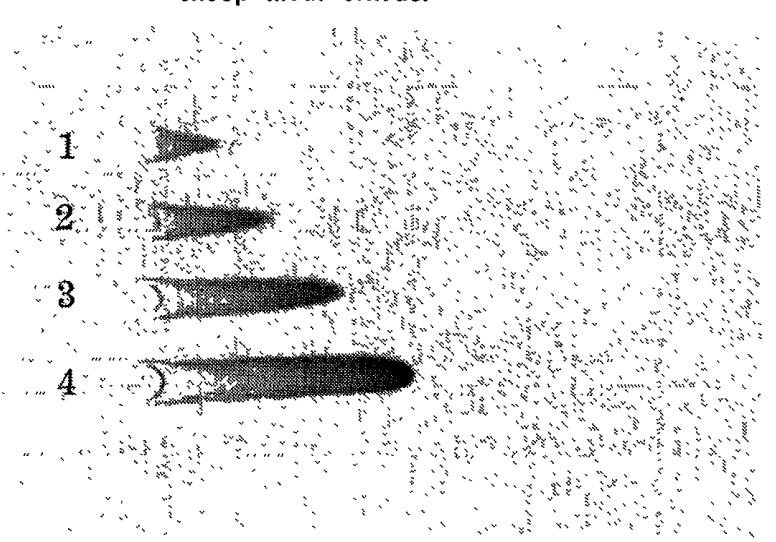

Remarks.

1, 40-fold; 2, 20-fold; 3, 10-fold and 4, 5-fold diluted sheep meat extract were submitted to the electrophoresis in agarose gel containing GSA-SSAcommon fraction $(80 \mu \mathrm{g} / \mathrm{ml})$. 
Fig. 3. Relationship between the concentration of meat extract and the distance of precipitate in rocket immunoelectrophoresis

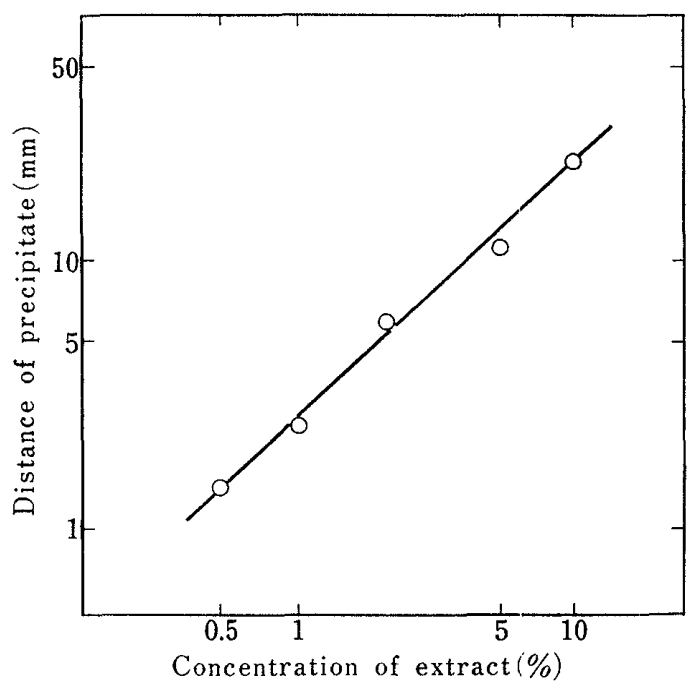

Remarks.

Diluted horse meat extract was submitted to the electrophoresis in agarose gel conkaining ESA-sp fraction $(80 \mu \mathrm{g} / \mathrm{ml})$.

Table 4. Determination of amount of adulterant by rocket immunoelectrophoresis*

\begin{tabular}{lcc}
\hline $\begin{array}{l}\text { Animal } \\
\text { species of meat }\end{array}$ & Ratio of mixing & $\begin{array}{l}\text { Distance of } \\
\text { precipitate }\end{array}$ \\
\hline Cattle thorse & $20: 80$ & $>55^{* *} \mathrm{~mm}$ \\
& $80: 20$ & 31 \\
Pig thorse & $20: 80$ & $>55$ \\
& $80: 20$ & 30 \\
Cattle + pig thorse & $45: 45: 10$ & 19 \\
\hline
\end{tabular}

Remarks.

* : The electrophoresis was carried out in agarose gel containing $80 \mu \mathrm{g}$ of ESA-sp fraction per $\mathrm{ml}$.

**: Apex of the precipitate overran from the agarose plate.

common fraction. The electrophoresis was carried out using 5- to 40 -fold diluted extract. The distances of precipitates were related to the concentration of the extract. Similar result was obtained by goat meat extract on the same agarose gel plate. Figure 3 illustrates the result of rocket immunoelectrophoresis obtained by diluted horse meat extract with agarose gel containing the ESA-sp fraction. A linear re-
Fig. 4. Determination of amount of adulterant by rocket immunoelectrophoresis

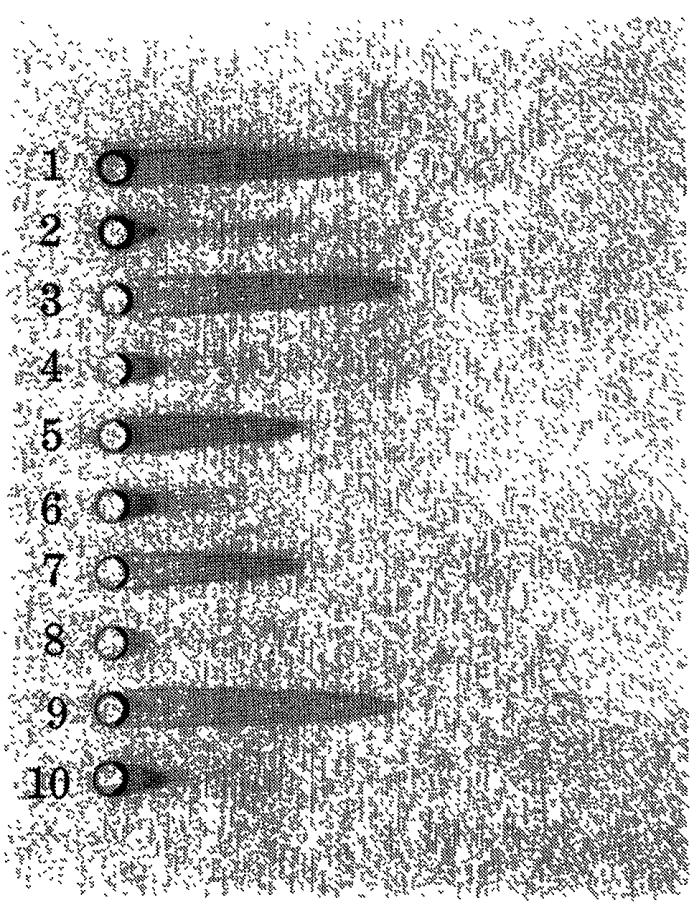

Remarks.

Agarose gel containing DSA-sp fraction $(80 \mu \mathrm{g} / \mathrm{ml})$ was used. Antigens used are as follows: 1, cattle + dog meat $(90: 10) ; 2$, cattle+dog meat $(99: 1)$; 3 , sheep+dog meat $(90: 10) ; 4$, sheep+dog meat $(99: 1) ; 5$, pig + dog meat $(95: 5) ; 6$, pig + dog meat $(99.5: 0.5) ; 7$, horse + dog meat $(95: 5) ; 8$, horse + dog meat (99.5:0.5); 9, cattle + pig + dog meat $(30: 60: 10)$; and 10, cattle tpig + dog meat $(30: 69: 1)$. Mixing ratio is indicated in parentheses.

lationship existed between the concentration of the meat extract and the distance of the precipitate. The identification limit was estimated to be $0.5 \%$ in concentration. It was also demonstrated by other sets of rocket immunoelectrophoresis that BSA-sp, PSA-sp, DSA-sp and CSA-sp fractions could form a precipitate only with their respective homologous single-meat extract with dose dependency. The identification limits were around $0.5-1.0 \%$ in concentration.

Various meat mixture containing 0.5$10.0 \%$ of dog meat were prepared and submitted to the rocket immunoelectrophoresis using an agarose gel containing the DSA-sp fraction (Fig. 4). The distances of precipi- 
Table 5. Determination of amount of adulterant by rocket immunoelectrophoresis

\begin{tabular}{|c|c|c|c|}
\hline \multirow{2}{*}{$\begin{array}{l}\text { Mixing ratio of } \\
\text { cattle meat: } \\
\text { pig meat }\end{array}$} & \multirow{2}{*}{ Dilution } & \multicolumn{2}{|c|}{$\begin{array}{l}\text { Distance of precipitate } \\
\text { in agarose gjel containing* }\end{array}$} \\
\hline & & $B S A-s p \quad f r$. & PSA-sp fr. \\
\hline \multirow{2}{*}{$80: 20$} & $\times 1$ & $>55^{* *} \mathrm{~mm}$ & 26 \\
\hline & $\times 10$ & 8.4 & 2.3 \\
\hline \multirow{2}{*}{$60: 40$} & $\times 1$ & $>55$ & $>55$ \\
\hline & $\times 5$ & 26 & 7.7 \\
\hline \multirow{2}{*}{$40: 60$} & $\times 1$ & $>55$ & $>55$ \\
\hline & $\times 5$ & 9.2 & 21 \\
\hline \multirow{2}{*}{$20: 80$} & $\times 1$ & 33 & $>55$ \\
\hline & $\times 10$ & 3.0 & 8.2 \\
\hline
\end{tabular}

Remarks.

*: Agarose gel containing $80 \mu \mathrm{g}$ of purified antibody fraction.

**: Apex of the precipitate overran from the agarose plate.

tates were $26-28 \mathrm{~mm}$ at $10 \%, 18-19 \mathrm{~mm}$ at $5 \%, 3-4 \mathrm{~mm}$ at $1 \%$, and $2-3 \mathrm{~mm}$ at $0.5 \%$ in concentration. This result indicated that the distance of precipitate depended only on the concentration of dog meat antigen, and that any other meat antigen contained in the mixture gave no effect on the distance. Table 4 indicates the result of the rocket immunoelectrophoresis conducted on meat samples containing 10, 20 or $80 \%$ of horse meat with the ESA-sp fraction. The distances of precipitates formed by antigens containing 10 or $20 \%$ of horse meat could be measured, but precipitates formed by antigens containing $80 \%$ of horse meat overran from the agarose plate. From this finding it was presumed that meat antigen might be diluted for the quantitative measurement of an adulterant contained in a large amount. To confirm this presumption, diluted and undiluted meat antigens composed of cattle and pig meats were studied with both BSA-sp and PSA-sp fractions (Table 5). When a mixture contained either meat in $20 \%$, the apexes of the precipitate formed by undiluted extract could be measured. When precipitates were formed by undiluted extracts containing either meat in $40 \%$ or higher, their apexes overran from the agarose plate. When the latter extracts were diluted to 5- or 10-fold, the apexes of the precipitates were measurable.

\section{Discussion}

For the serological identification of the animal species of meat, much effort has been given to the preparation of speciesspecific antiserum $[2,7,8,10,11]$. For this purpose, a heat treatment of immunizing antigen or an adsorption technique has been studied. However, the species-specificity of these antisera was not always strict and some degree of cross-reactivity demonstrated.

In this experiment, a species-specific antibody fraction against BSA, PSA, ESA, DSA or CSA was obtained rather easily by immunoadsorbent chromatography, while such fraction against GSA or SSA could not be purified. These results are in agreement with those obtained from the previous studies a close antigenic resemblance was indicated between GSA and SSA [3, 4]. In some cases, a small amount of speciesspecific antibody fraction against SSA could be obtained by careful chromatography, but the precipitin line formed by this antibody and sheep meat extract was very faint (unpublished data). In the present experiment, therefore, a GSA-SSA-common fraction, which react with both GSA and SSA but not with serum albumin of any other animal species, was used to differentiate the meat of the goat-sheep group from that of any other animal species.

For the identification of a single animal species, the effectiveness of the purified antibody fractions was revealed by two techniques, the ring test and the rocket immunoelectrophoresis. The two methods 
were almost at the same level of identification limit under the present experimental conditions. As for the quantitative identification, rocket immunoelectrophoresis is superior to any of the conventional methods including the passive hemagglutination inhibition test [6]. In the electrophoresis, samples in the concentration of $0.5-80.0 \%$ formed precipitates. The distances of the precipitates were correlated with the concentration of the adulterant. When this concentration was high, it was required to dilute the extract for estimation of the mixing ratio. Although no data were presented here, it was found that agarose gel containing a large amount of antibody $(320 \mu \mathrm{g} / \mathrm{ml})$ served effectively for the detection of adulterants contained in a high concentration.

As reported previously [6], the passive hemagglutination inhibition test with crossreacting antisera is regarded as an excellent technique for the detection of a trace amount of meat antigen, but is not so satisfactory a method for the quantitative measurement of an adulterant. On the other hand, the rocket immunoelectrophoresis is an efficient method for quantitative determination of an adulterant. It is, however, less sensitive for a trace amount of meat antigen than the passive hemagglutination inhibition test. It is considered, therefore, that both or either one of the two methods should be chosed for the identification of the animal species of meat, as occasion demands.

\section{References}

[1] Butler, W. T. (1963). Hemagglutination studies with formalinized erythrocytes. Effect of bis-diazotized-benzidine and tannic acid treatment of sensitization by soluble antigen. J. Immunol., 90, 663-671.

[2] Ishikawa, J. (1960). A study on the species specificity of the animal sera. Hokkaido $J$. med. Sci., 35, 237-253 (in Japanese with English summary).

[3] Kamiyama, T. (1977). Immunological crossreactions and species-specificities of bovine, goat and sheep serum albumins. Immunochemistry, 14, 85-90.

[4] Kamiyama, T. (1977). Immunological crossreactions and species-specificities of cyanogen bromide cleaved fragments of bovine, goat and sheep serum albumins. Immunochemistry, 14, 91-98.

[5] Kamiyama, T., Katsube, Y., and Imaizumi, K. (1978). Serum albumin contents in meat extracts in relation to serological identification of animal species of meats, Jap. J, vet. Sci., 40, 559-563.

[6] Kamiyama, T., Katsube, Y., and Imaizumi, K. (1978). Serological identification of animal species of meats by a passive hemagglutination inhibition test using cross-reacting anti-serum albumin antiserum. Jap. J. vet. Sci., 40, 653661.

[7] Kaplan, E., and Buck, T. C., Jr. (1951). Detection of horse meat by the biological precipitin test. J. Milk Food Tech., 14, 66-67.

[8] Katsube, Y., and Imaizumi, K. (1968). Serological differentiation of animal meats. Jap. J. vet. Sci., 30, 219-232.

[9] Laurell, C.-B. (1966). Quantitative estimation of proteins by electrophoresis in agarose gel containing antibodies. Analyt. Biochem., 15, $45-52$.

[10] Pinto, F. C. (1961). Serological identification of ox, buffalo, goat and deer flesh. Brit. vet. J., 117, 540-544.

[11] Proom, H. (1943). The preparation of precipitating sera for the identification of animal species. J. Path. Bact., 55, 419-426.

[12] Weinstock, A. (1953). A survey on the detection of horsemeat by the serological precipitin test. J. Milk Food Tech., 16, 257-259. 